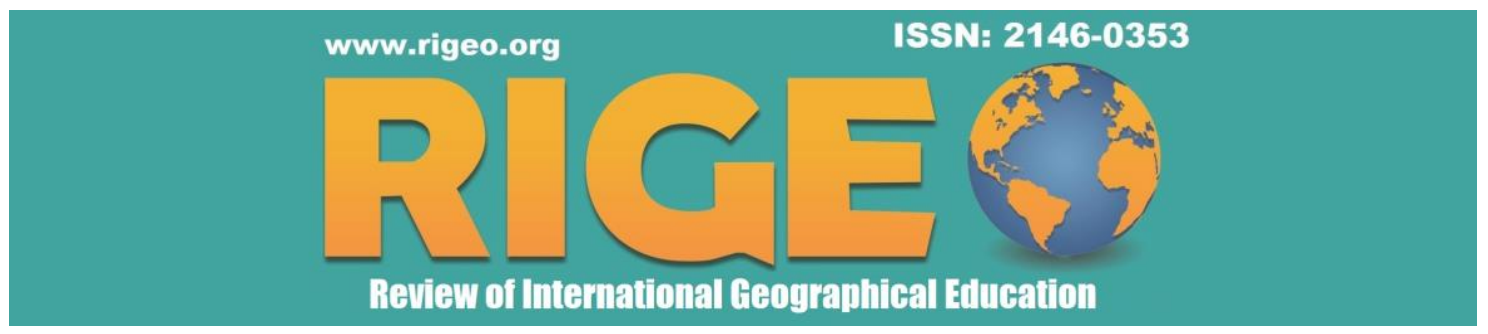

(C) RIGEO, Volume 10, Issue 1 (Special Issue), 2020

Research Article

Copyright $\odot$ RIGEO 2020

To cite this article: Kocalar, A., O.; Bilgili, M. (2020). Opinions of Geography Teacher Candidates about Energy Resources: A Critical Phenomenological Approach. Review of International Geographical Education (RIGEO), 10, (1), Special Issue, 159170. Retrieved from http://www.rigeo.org/vol10no1/Number1Spring/RIGEO-V10-N1-8.pdf

DOI: 10.33403 rigeo.641546

Submitted: November 01, 2019

Revised: December 12, 2019

Accepted: February 04, 2020

\title{
Opinions of Geography Teacher Candidates about Energy Resources: A Critical Phenomenological Approach*
}

\author{
Ali Osman KOCALAR ${ }^{1}$ \\ Marmara University, İstanbul, TURKEY \\ Münür BİLGİंí2 \\ Marmara University, İstanbul, TURKEY
}

\begin{abstract}
Energy is mentioned as a concept that affects the policies of the country with the consumption of natural resources, with the production types in alternative and different ways, and with the effect of the economy of the countries. It is offered in various courses from primary school to university, teaching of energy sources. And while this is also important as a field of expertise, energy resources are taught as a course in many universities in undergraduate education. It was necessary to do such a study, to determine the general knowledge and behavior of Geography teacher candidates within the scope of energy resources course. This study is a case study of qualitative research methods. Qualitative research is the method by which data is produced without statistical operations or any other numerical means in any way. In addition, the qualitative research method is focused on one main case and based on the opinions of the participants. It is important to have flexibility in the research designed and to have an inductive analysis, qualitative research techniques. The case study is an in-depth description and examination of a limited system. In this study, in-depth and detailed views of the Energy Resources course were taken from the geography teacher candidates during the undergraduate period. Phenomenology design, one of the qualitative research methods, was used in the study. The desire to convey the candidates' views more clearly and clearly is the reason why we use this design. Critical approach has also been used in the interpretation of phenomenological design. We did this to broaden our perspective on the study.

Keywords

Geographical Education, Teacher Candidate, Energy Resources
\end{abstract}

*A portion of this research was presented in 2. International Congress on Geographical Education (UCEK/ICGE-2019), 3-5 October 2019, Eskişehir-Turkey.

${ }^{1}$ Corresponding author: Assoc. Prof., Marmara University, Ataturk Education Faculty, Department of Geography Teaching, Istanbul, Turkey, ali.kocalar [at] marmara.edu.tr., ORCID: 0000-0002-7827-9043

${ }^{2}$ Assoc. Prof., Marmara University, Ataturk Education Faculty, Department of Geography Teaching, Istanbul, Turkey, munur.bilgili [at] marmara.edu.tr., ORCID: 0000-0002-6841-4926 
In Geography courses, which include the classical understanding of geography, energy is often emphasized about how strategic energy is and how important it is in development. We find it incomplete, even though we find some truth in that view. While we often forget the human factor in development; we focus more on the source. In a sense, we advocate a deterministic approach. Therefore, in the approach we will express in the study, we will try to explain the relatedness between source and human in a more balanced dimension.

They are trying to make use of different energy sources, countries to provide their energy needs. However, when determining energy policies today, it is aimed to use energy types that minimize environmental problems as well as to meet energy needs in the best way. There is more interest today because of global warming and increasing environmental problems, renewable energy sources solar energy, wind energy, geothermal energy, hydro energy, sea-wave energy and biomass energy.

It causes rapid demand for energy, rapid population growth and industrialization in developing countries. Energy is an essential factor of production and one of the main indicators that reflect the economic and social development potential of a country. There is a linear relationship between energy consumption and social development, and it is observed that energy consumption increases with economic development and prosperity (Koç and Şenel, 2013:33).

People's need for electricity is increasing every day, due to factors such as population growth, urbanization, industrialization and changes and developments in technology (Palabıyık, Yavaş and Aydın, 2010). The energy that is used in all areas of daily life can be found in various forms such as chemical, nuclear, mechanical, thermal, geothermal, hydraulic, solar, wind, electrical energy.

Energy sources are divided into renewable and non-renewable energy sources according to their usage. Energy sources that are projected to be depleted in the future are two separate, non-renewable energy sources, fossil-derived and core-derived. Renewable energy sources are energy sources that will maintain their existence in a very long period. According to the state of conversion, primary and secondary energy sources are examined. The primary energy of a system is the energy of a system. These are oil, coal, natural gas, nuclear, hydraulic, biomass, wave-tide, solar and wind. The energy obtained from the conversion of primary energy is also defined as secondary energy. Electricity, petrol, diesel, metallurgical coal, secondary coal, petrokok, air gas, liquefied petroleum gas (LPG) are among these types of energy sources (Şenel, 2012).

The introduction of new energy production facilities is inevitable because increased energy consumption and external dependence force countries to use energy sources that both best address their energy needs and reduce environmental and human health problems (Curry, Reiner, Figueiredo and Herzog, 2005; Ediger and Kentmen, 2010; Özalp, Kurdoğlu, Yüksel and Yıldırımer, 2010).

The aim of this study is to reveal the approaches of the teacher candidates to the subject of energy with a phenomenological approach. According to this approach, it will be to clarify how the candidates form their ideas on the subject, what these ideas mean 
and how they can be transformed. The study will be considered in an interpretive and critical phenomenological manner.

The problem statement of the study is as follows: What are the geography teacher candidates' views on energy sources?

\section{Method}

\section{Research Design}

This study is a case study of qualitative research methods. Qualitative research is the method by which data is produced without statistical operations or any other numerical means in any way (Altunışık, Coşkun, Bayraktaroğlu and Yıldırım, 2005). In addition, the qualitative research method is focused on one main case and based on the opinions of the participants (Creswell, 2012).

In the process of establishing the theoretical framework and methodological basis of this work, critical phenomenological approach has been utilized. Phenomenology focuses on how individuals experience, feel and make sense of phenomena. It is an interpretive approach and takes into account our sensuous experiences in everyday life (lifeworld) (Alvesson and Sköldberg, 2017). Aims to create an objective narrative from the subjective lives of individuals (Blaikie and Priest, 2017). Rather than our explanation of the facts, it gives importance to how the participants live and describe this phenomenon. Therefore, phenomenological writing has a reflective/reflective property (Van Manen, 2016). It deals with the relatedness between the conscious being and the phenomena. Consciousness does not exist only as consciousness; consciousness is necessarily related to certain facts and objects (Crotty, 1998). Studies using this approach (phenomenological) focus on how the relevant phenomenon is expressed and how it occurs, rather than entering the mind of the participants (Vagle, 2016). Because we do not perceive the world directly (Pernecky, 2016) what we experience constitutes the social reality that we leave in our minds and how we make sense of them. Phenomenology attempts to explain the fundamental structures of these human experiences (Brinkmann, 2017). When making these statements, it is important that scientists' ideas and thoughts about the cases studied are not included as much as possible (Cohen, Manion, and Morrison, 2017), as it is important how the participants make sense of the relevant cases. Critical phenomenology is more dialectical and interpersonal/intersubjective. It focuses not only on how the primary individual lives and makes sense of the facts, but also on how the facts appear through interactions between individuals. What makes phenomenology critical at this point is that it is more intersubjective (Salamon, 2018).

It is important to have flexibility in the research designed and to have an inductive analysis, qualitative research techniques (Yıldırım and Şimşek, 2011). The case study is an in-depth description and examination of a limited system (Merriam, 2015). In this study, in-depth and detailed views of the Energy Resources course were taken from the geography teacher candidates during the undergraduate period. 


\section{Working Group}

The study group consists of 15 geography teacher candidates studying at a state university in İstanbul in the spring semester of 2018-2019. The students in the study group were considered to be among the students who took the energy resources course in undergraduate education. The pilot application was made with 5 students before the application was made.

\section{Data Collection Tools}

In this study, a semi-structured interview form was applied to the participants as a data collection tool. Because of the flexibility they have, semi-structured interview forms eliminate the limitation on writing and filling-in Tests and questionnaires and help to gain in-depth knowledge of a specific topic.

The suitability of the questions for the interview was discussed after the pilot study of the interview form was made. In the interview form, answers were sought from the teacher candidates to the following questions: What are the sources of energy? Why is energy needed? What do we understand when we say types of energy? What should be done for renewable energy generation? What do you think of the future of energy? How can alternative energy sources be obtained?

Before the interview form was applied, the researcher explained the purpose of the study to the working group and reminded that if the participant is not a volunteer, they can cease participation at any time. They have been informed in advance for interviews conducted using the interview form, which takes its final form. The talks lasted between about 20 and 30 minutes.

\section{Analysis of the Data}

For data analysis, content analysis technique was used. The main purpose of content analysis is to reach concepts and relationships that can explain the collected data. Content analysis was started by repeatedly examining the documents obtained from the participants. The review process was conducted by two researchers.

In the data examined, the aspects that stand out and are considered to be of importance were determined and first codes and then categories were obtained. The code and categories were then clarified by comparing the code and categories produced separately by both researchers. The research process has been detailed to ensure external validity. Direct citations of student responses in the current study are presented with no changes. In short, the findings were described systematically and clearly and the descriptions were arranged.

In order to ensure the validity of data collection and analysis, attention has been paid to the resulting data being consistent and meaningful in itself. Therefore, the purpose of the research, the consistency between the data collection tool and the data analysis were taken into account at all stages from the beginning to the end of the study. The data collection tool used in the study was prepared based on literature review, presented to expert opinion and tested in trial interviews and given its final shape (Akbiylk and Kalkan Ay, 2014). The coding process and the identification of themes were compared 
by both researchers separately, thus efforts were made to increase the validity and reliability of the data analysis process.

\section{Findings}

The answers received from the students were carefully examined and the necessary arrangements were made. Particular attention has been paid to the creation of a list of concepts representing students' perceptions from the data received. Each question was examined separately and evaluated and presented as a finding below.

\section{Sources of Energy}

As the source of energy, they provided information in a way that created different topics, participants. Therefore, as shown in Table 1, energy sources are grouped as mines, water, magma, sun and organic matter.

Natural gas, petroleum, lignite, uranium and thorium, which are derived from the mines themselves, are mentioned as sources of energy by the participants. The energy source obtained from water power is specified as stream (hydroelectric), wave and tidal. There are also those who indicate the power of magma as geothermal energy. Solar and wind energy are the source of energy from the sun and biomass from organic matter is stated as the source of energy.

Table 1

Student views on the sources of energy

\begin{tabular}{lc}
\hline Concepts & Frequency \\
\hline Mines; natural gas, petroleum, lignite, uranium, thorium. & 5 \\
Water; streams, waves, tides. & 3 \\
Magma; geothermal. & 1 \\
Sun; Sun, wind. & 3 \\
Organic matter; biomass. & 3 \\
\hline
\end{tabular}

Some quotes taken directly from participants are as follows:

K2: "Energy sources are sources that enable the production of energy by any method."

K5: "Energy resources natural gas, petroleum, coal and types of coal, nuclear energy, solar energy, wave energy, wind energy, hydroelectric energy, geothermal energy, biomass energy."

K11: "There are two kinds of sources of energy available in our world. These are renewable and non-renewable energy sources."

K12: "It is called the sources that enable the production of energy."

\section{Why is Energy Needed?}

Energy has become an important force in every moment of life today. A life without energy has been unthinkable in recent years. Therefore, the information obtained and given in Table 2 appears in this direction. Participants stated that energy is needed for meeting needs, making life easier, industrialization, growth and development, and this will continue to increase. 
Table 2

Student views on energy need

\begin{tabular}{lc}
\hline Concepts & Frequency \\
\hline For the meeting your needs & 5 \\
For the development and growth & 2 \\
For the science and industry & 2 \\
For the standard of living to increase & 3 \\
For the make life easier & 3 \\
\hline
\end{tabular}

Some citations received from the participants are as follows:

K1: "We need energy for pretty much everything we do."

K3: "Energy resources are very important in terms of economic growth, industrialization, and people's living standards."

K6: "Energy is needed for people to be able to sustain their lives and meet their various needs."

K12: "Energy resources are very important in terms of economic growth, industrialization and increasing people's living standards."

K14: "We absolutely need energy in everything from production to consumption with industrial organizations."

\section{Types of Energy}

In general, types of energy are classified as renewable and non-renewable energy sources. Renewable energies are known as non-ending, self-renewing, and repeatedly obtained energies, whereas energy that cannot be used again and ends after being used is called non-renewable energies. The information obtained from the participants regarding the types of energy is given in Table 3.

Table 3

Student views on energy types

\begin{tabular}{lc}
\hline Concepts & Frequency \\
\hline Renewable energy & 6 \\
Electrical energy & 2 \\
Nuclear energy & 3 \\
Non-renewable energy & 4 \\
\hline
\end{tabular}

Some quotes taken directly from participants are as follows:

K6: "When we say types of energy, we understand renewable and non-renewable energy sources."

K8: "Energy types are divided into renewable energy and non-renewable energy. Geothermal, solar, wind, hydraulic and biomass renewable energies; coal, oil, natural gas, uranium, thorium are non-renewable energies."

K11: "When we say types of energy, we think of renewable and non-renewable energy sources."

K14: "Basically, when we say energy, it comes to mind sources such as oil, natural gas, coal and lignite, which we call non-renewable energy sources." 


\section{What Should Be Done for Renewable Energy Generation?}

The use of renewable energy sources is very important for humanity. Therefore, renewable energy production should be encouraged and especially financial facilities should be provided for transportation to renewable sources. The data obtained from the participants were in line with this.

As can be seen in Table 4, concepts such as the state should encourage, act consciously, encourage renewable resources, and determine the potential of countries in terms of renewable energy sources come to the fore.

Table 4

Student views on renewable energy generation

\begin{tabular}{lc}
\hline Concepts & Frequency \\
\hline The state should encourage & 3 \\
Determination of new sources & 3 \\
Awareness-awareness & 2 \\
Directing-encouraging-obliging companies & 2 \\
Emphasis on trust and cleanliness & 1 \\
Determination of the country's potential & 3 \\
\hline
\end{tabular}

Some opinions taken directly from the participants are as follows:

K1: "Companies should be channeled into these areas and the public should be informed about the use of renewable energy, and the state should give serious incentives and support to legal and private companies to operate in this area."

K8: "More incentives and efforts are needed for renewable energy generation."

K12: "Identification of resources and fieldwork are important for production."

K14: "First of all, the country's location, latitude must be determined whether it is suitable for renewable energy production."

\section{Future of Energy}

Today, the rapidly increasing population due to the development of living conditions and the resulting increased energy consumption have led us to worry that fossil resources may be depleted in the near future. On the one hand, the growing worldwide carbon footprint due to the high use of fossil fuels has also become inconsiderable. Accordingly, the orientation towards renewable energy sources has started.

When we look at the future plans and policies of the countries, it is seen that many tend to diversify their energies and focus on renewable energy.

The consumption of resources is increasing rapidly and there is a lot of damage to nature because of the users who are thinking of unlimited growth using limited resources. Participants ' views on the future of energy are given in Table 5. 
Table 5

Student views on the future of energy

\begin{tabular}{lc}
\hline Concepts & Frequency \\
\hline There will be a shift towards alternative energies & 3 \\
Energy efficiency will increase & 2 \\
Energy resources will be reduced & 2 \\
Fossil fuels will run out & 2 \\
Energy will be needed more & 2 \\
New types of energy to be discovered & 3 \\
\hline
\end{tabular}

Some opinions taken directly from the participants are as follows:

K1: "With the introduction of unprecedented technologies and the introduction of stricter energy policies by states, there will be huge productivity gains."

K7: "Considering the increasing population and the increasing needs in parallel, it feels like we are nearing the end."

K9: "With the development of Science, new energy systems are being established and will be freed from dependence on deplorable energy sources such as oil and natural gas."

K15: "I think very negatively because I don't think States will care enough about renewable energy sources and give up on their ambitions."

\section{How Do Alternative Energy Sources Produced?}

In the developing world, a rapid production and consumption frenzy through technology and industry will surely drive people to alternative methods when the available types of energy are exhausted over time.

People's instinct to preserve the existing world and environmental order will drive him to produce a variety of energy that will not harm nature, such as fossil resources. The emergence of electric cars, for example, is an example of this. In other words, when a person is in a difficult situation, thinking about the interests of himself and his people and therefore his country, he will bring out alternative energy sources.

As shown in Table 6, the participants made very different proposals for alternative energy production. Among these suggestions are the development of new methods to be made with scientific studies, technological development and facilities, the acquisition of new resources from space, magma and natural systems, and the provision of productivity in production.

Table 6

Student views on the production of alternative energy sources

\begin{tabular}{lc}
\hline Concepts & Frequency \\
\hline New methods & 5 \\
Scientific works & 3 \\
Productivity in production & 2 \\
Geographic location & 1 \\
Developing technological facilities & 4 \\
\hline
\end{tabular}


Some citations received from the participants are as follows:

K3: "These resources can be obtained from space, human power, magma and natural systems."

K8: "Depending on the development of scientific and technological facilities, efforts to produce alternative sources will increase."

K10: "First of all, he needs to know his place very well. It should be acted on the logic of how to provide less harm, much yield. Countries need to analyze themselves from their position to their advantage."

K11: "Taking advantage of emerging technological opportunities can be very effective in the production of new energy sources."

K14: "In fact, when people are in trouble, they have always produced something."

\section{Result}

Generally, candidates are often seen to develop a certain awareness of energy sources, but some fundamental problems are noted. As Sovacool and Jefferson (2018) point out, there are parallels between overall energy use and economic growth in the world. As such, economic growth has been constantly taken into account in terms of energy and placed in a narrow framework. We can also see traces of this view in the answers of the teacher candidates. Candidates have a hard time coming out of the energy-growth dilemma, so their perspectives focus on a narrower point.

Although some candidates take a different approach on this issue, some general problems remain. The most important of these points is that they do not draw much attention to the economic, political and social power relations that exist in the world regarding energy.

It is often overlooked that an important part of the problems related to energy are related to the functioning of the capitalist world system. As Wallerstein (1987) mentions in his theory of world systems, the world in general consists of central, peripheral, and semi-peripheral countries. This process is related from birth to the functioning, distribution and consumption of energy. The relevant point is not generally visible in candidates.

There is a close relatedness between population and energy. The increasing world population will further increase the pressure on energy resources, according to participants. Therefore, they see turning to alternative energy sources as a solution. Renewable energy sources are considered to be the most important element in these sources. The K8 participant draws attention to the population-energy relationship with the idea that" however, the rapidly increasing population due to the development of living conditions and the resulting increased energy consumption have led us to worry that fossil resources may be depleted in the near future " and sees this as a source of concern. The participant, coded K5, shares the pessimistic view, saying, " the future of energy does not look very bright." Participants generally view energy shortages as a major problem due to population growth.

Some awareness of the students about energy sources (Aydın and Kocalar, 2014) has been established. The population-energy relatedness described above, the move towards depletion of renewable energy sources, the existence of alternative energy 
sources, or the emphasis on the availability of scientific developments can be seen as signs of increased awareness. Participants also note that states do not invest much in renewable energy sources. For example, the K15-coded participant considers States' indifference to the issue as a problem, saying, "I think very negatively because I don't think States will care enough about renewable energy sources and give up their ambitions."

In this study participants have almost a common opinion on the existence and efficiency of alternative energy sources. According to them, new methods to be developed depending on the developing technology are the most important tools for reaching alternative sources. The user with the code K11 points out the connection between technological development and new energy sources by saying, "taking advantage of the technological possibilities can be very effective in the production of new energy sources." "The emergence of electric cars, for example, is an example of this," said the participant with the code K14. In this finding, some students consider taking advantage of the advantages of geographical conditions as a way out.

What should be done for renewable energy generation? The answers given to the question are noteworthy in the way that an emphasis should be placed on raising awareness through education. Participants have identified close correlations between education and energy. "First of all, people and authorities should be made aware that irreversible damage can occur in our world if non-renewable energy sources are used more," said the K11 participant, stressing the importance of raising awareness. Similarly, the participant with the code K6 suggested that " first of all, it is necessary to raise awareness of people in terms of renewable energy sources". From these citations one can infer that the participants share the view that there is a lack of training on alternative energies.

The present and future states of energy sources are thought to be obtained not only at the cognitive level but also as attitudes and behaviors. It is very important for the future of the country for the participants to have new ideas on alternative energy consumption and production for the future. According to the results obtained from the participants, more than the total amount and types of energy possessed, it is necessary to form views towards the protection of natural resources, which is a guarantee of the future of the world and humanity. 


\section{References}

Akbiyık, C. \& Kalkan Ay, G. (2014). Perceptions of pre-school administrators and teachers on thinking skills instruction: a case study. H. U. Journal of Education, 29 (1), 01-18.

Altunışık, R., Coşkun, R., Bayraktaroğlu, S. \& Yıldırm, E. (2005). Research methods in social sciences: applied spss. 4th Edition. Sakarya Publishing.

Alvesson, M. \& Sköldberg, K. (2017). Reflexive methodology: new vistas for qualitative research. SAGE Publications.

Aydın, F. \& Kocalar A. O. (2014). The attitudes of the students of geography department toward renewable energy sources. J. Int. Environmental Application Science. Vol. 9(3): 389-397.

Blaikie, N. \& Priest, J. (2017). Social research: paradigms in action. Wiley.

Brinkmann, S. (2017). Philosophies of qualitative research (understanding qualitative research). Oxford University Press.

Cohen, L., Manion, L. \& Morrison, K. (2017). Research methods in education. Taylor and Francis.

Creswell, J. W. (2012). Qualitative inquiry and research design: choosing among five approaches. SAGE Publication.

Crotty, M. J. (1998). The foundations of social research: meaning and perspective in the research process. SAGE Publications.

Curry, T., Reiner, D., Figueiredo, M. \& Herzog, H. (2005). A survey of public attitudes towards energy and environment in Great Britain. Mascashusetts Institute of Technology Laboratory for Energy and Environment. https://sequestration.mit.edu/pdf/LFEE_2005001_WP.pdf

Ediger, V.Ş. \& Kentmen, Ç. (2010). Social dimension of energy and energy choices of turkish public, The Mülkiye Journal, 34(268): 281-300.

Koç, E. \& Şenel, M. C. (2013). The state of energy in world and turkey - general evaluation, Engineer and Machine, 54(639): 32-44.

Merriam, S. B. \& Tisdell, E. J. (2015). Qualitative research: a guide to design and implementation. Wiley.

Özalp, M., Kurdoğlu, O., Yüksel, E. E. \& Yıldırımer, S. (2010). Ecologic and social problems caused by run-of-river type hydroelectric power plants in Artvin, III. The National Karadeniz Forestry Congress, (II): 677-687.

Palabıyık, H., Yavaş, H. \& Aydın, M. (2010). Can a nuclear power plants be constructed in turkey? from conflict to agreement: the social acceptance problem of nuclear energy projects in Turkey and analysis the investigation of public refusal syndrome. Journal of Entrepreneurship and Development, 5 (2): 175-201.

Pernecky, T. (2016). Epistemology and metaphysics for qualitative research. SAGE Publications

Salamon, G. (2018). What's Critical about Critical Phenomenology? Retrieved from http://journals.oregondigital. org/index.php/pjcp/article/view/PJCP.v1i1.2/4435 
Şenel, M. C. (2012). The design principles of power transmission mechanisms in wind turbines - dynamic behavior. (Unpublished Master Thesis). Ondokuz Mayss University Institute of Science and Technology, Samsun.

Sovacool, B. K. \& Jefferson, M. (2018). "Energy studies" in companion to environmental studies. Castree, N., Hulme, M., Proctor, C., D. (eds). Taylor and Francis.

Vagle, Mark D. (2016). Crafting phenomenological research. Taylor and Francis.

Van Manen, M. (2016). Phenomenology of practice: meaning-giving methods in phenomenological research and writing. (Developing Qualitative Inquiry). Taylor and Francis.

Wallerstein, I. (1987). "World-systems analysis", in A. Giddens y J.H. Turner (eds.), Social Theory Today, Cambridge, Polity Press, pp. 309-324.

Yıldırım, A. \& Şimşek, H. (2011). Qualitative research methods in the social sciences. Ankara: Seçkin Publishing.

\section{Biographical Statements}

Ali Osman KOCALAR is an associate professor in the Marmara University, Atatürk Education Faculty, and Department of Geography Education. His research interests are teaching strategies, geography education and environment education.

Münür BİLGÍLi is an associate professor in the Marmara University, Atatürk Education Faculty, and Department of Geography Education. He studies on geography education, cultural geography, philosophy of geography and philosophy of social sciences. 